\title{
Stage IVA Thyroid Gland Medullary Carcinoma AJCC v7
}

National Cancer Institute

\section{Source}

National Cancer Institute. Stage IVA Thyroid Gland Medullary Carcinoma A/CC v7. NCI

Thesaurus. Code C87549.

Stage IVA includes: (T4a, N0, M0); (T4a, N1a, M0); (T1, N1b, M0); (T2, N1b, M0); (T3, N1b, M0); (T4a, N1b, M0). T4a: Moderately advanced local disease. Tumor of any size extending beyond the thyroid gland capsule to invade subcutaneous soft tissues, larynx, trachea, esophagus, or recurrent laryngeal nerve. T1: Tumor size $2 \mathrm{~cm}$ or less in greatest dimension, limited to the thyroid gland. T2: Tumor more than $2 \mathrm{~cm}$ but not more than $4 \mathrm{~cm}$ in greatest dimension, limited to the thyroid gland. T3: T umor more than $4 \mathrm{~cm}$ in greatest dimension and limited to the thyroid gland, or tumor of any size with minimal extrathyroid extension (e.g., extension to sternothyroid muscle or perithyroid soft tissues). T4b: Very advanced disease. Tumor invades prevertebral fascia or encases carotid artery or mediastinal vessels. N0: No regional lymph node metastasis. N1a: Metastasis to pretracheal, paratracheal or prelaryng eal/Delphian lymph nodes (Level VI lymph nodes). N1b: Metastasis to unilateral, bilateral or contralateral cervical (Levels I, II, III, IV, or V) or retropharyngeal or superior mediastinal lymph nodes (Level VII). M0: No distant metastasis. (AJCC 7th ed.) 